\title{
Blessing in Disguise or Bluffing in This Guide: CDA on the Chinese Language Education Policy for Ethnic Minority Students in Hong Kong
}

\author{
Emil Li ${ }^{1, *}$ \\ ${ }^{1}$ Graduate School of Education, Faculty of Social Sciences and Law, University of Bristol, \\ Bristol, United Kingdom \\ *Correspondence: Graduate School of Education, Faculty of Social Sciences and Law, \\ University of Bristol, Bristol, United Kingdom. E-mail: emilli@vtc.edu.hk
}

Received: July 15, 2020 Accepted: August 6, 2020 Published: August 28, 2020

doi:10.5296/ije.v12i3.17234 URL: https://doi.org/10.5296/ije.v12i3.17234

\begin{abstract}
Language reflects ideologies, so does imagery. This paper attempts to uncover the underlying ideologies behind the visual and verbal signs of the brochure titled "Non-Chinese Speaking Parent Information Package: Your Guide to Education in Hong Kong" produced by the Education Bureau, Hong Kong Special Administrative Region. The brochure was carefully read and interpreted through the lens of Critical Discourse Analysis. The author is interested in how the underpinning ideologies and proposed support measures paint a beautiful and promising education picture for ethnic minority students and their parents in Hong Kong.

Keywords: learning Chinese as a foreign language, ethnic minority education, education policy, non-Chinese speaking
\end{abstract}




\section{Introduction}

Critical Discourse Analysis is used in this paper to examine the fusion of visual and textual signs of the brochure titled "Non-Chinese Speaking Parent Information Package: Your Guide to Education in Hong Kong" (Note 1) issued by the Education Bureau (EDB), Hong Kong Special Administrative Region (HKSAR), in an attempt to decode the intended and unintended messages for the social agent, i.e. non-Chinese speaking parents, who are confronted by this so-called guide and may faithfully trust that it is necessary, informative and helpful to them and their children. It is hoped that this paper goes beyond the visual and textual signs to unveil the true picture of Chinese language education for ethnic minorities (EM) in Hong Kong. Section 2 provides an up-to-date synopsis of the education and employment opportunities for ethnic minorities in Hong Kong. Section 3 outlines the literature review on (1) the recent criticisms against the Chinese language education policy, and (2) the use of Critical Discourse Analysis (CDA) for education policies. Section 4 presents and discusses the analysis of the visual and verbal signs extracted from the brochure. Finally, Section 5 concludes the whole analytical studies of this paper.

\section{Background}

Education is the key to the future. Not only does it enable individuals to fully unleash their potentials and capabilities, it is also instrumental in realising attainment in other areas such as employment and indeed, life in general. In Hong Kong, all eligible local children are entitled to 12 years of free education, 9 of which are compulsory. Although Hong Kong has been enjoying international praise for its sound education system, one of the most disgraceful and pressing issues in the local public education arena today is the persistent underachievement and neglect of ethnic minority students. This is repeatedly evidenced by literature and press articles complaining about inequity and deprivation of social rights regarding educational provision for EM students in the territory (Benitez, 2011; Cheng, 2011; Chong, 2011; Hong Kong Unison, 2012; Hue, 2011; Thapa, 2012). Below provides an up-to-date synopsis of the situation that EM students in Hong Kong are facing.

\subsection{Ethnic Minorities in Hong Kong}

Ethnic minorities in Hong Kong refer to persons of non-Chinese ethnicity. They have long been present since the beginning of the British colonial governance (Pluss, 2000), and later classified as subgroups of Hong Kong's population by the HKSAR Government. According to the 2016 Population By-census (Census and Statistics Department, 2017), the population of ethnic minorities in Hong Kong is 584,383, accounting for $8 \%$ of the total population. Ethnic minority groupings are based upon geographical classification and consist of Filipinos (31.5\%), Indonesians (26.2\%), Whites (10\%), Indians (6.2\%), Nepalese (4.6\%), Pakistanis (3.1\%), Thais (1.7\%), and Japanese (1.7\%). In the Hong Kong government context, the white race are Caucasian people from western countries including the United Kingdom, the United States of America, Canada, Australia, New Zealand and Europe (Census and Statistics Department, 2017). 


\subsection{Education and Assessment of the Chinese Language}

Ethnic minority students are classified as non-Chinese speaking (NCS) children by the EDB. There are 9,849 NCS primary pupils and 9,481 NCS secondary students in 2018/2019, accounting for about 3\% of Hong Kong's school age population. In fact, the majority of NCS students come from South-east Asian or South Asian countries, which are regarded as ethnic minorities by the general public. According to the recent report on Education for Ethnic Minorities by the Equal Opportunities Commission (EOC), the presence of EM students in the post-secondary level is comparatively low. Despite having an equal right to education, the number of EM students attaining a higher level of education is disproportionately low compared with the majority local ethnic Chinese.

At present, most EM students are placed in local primary and secondary public schools; over $90 \%$ of them are studying mainstream curriculum including the Chinese language subject adjusted and modified by these schools on an as-needed basis (Curriculum Development Council, 2008). The EDB reiterates its current mandatory Chinese language curriculum for these schools is flexible and thus insists on the use of it. Later, a supplementary Chinese language guide and the Chinese Language Curriculum Second Language Learning Framework were issued in 2008 and in 2014 respectively to supplement pedagogy, principles and recommendations for implementing the Chinese language curriculum in the educational context of these NCS students.

Meanwhile, while the EDB tries to maintain the noble status of the Chinese language curriculum, it then allows NCS secondary leavers to sit for the British General Certificate of Secondary Education (GCSE) Chinese Language examination, the International General Certificate of Secondary Education (IGCSE) Chinese Language Examination and the General Certificate of Education (GCE) Chinese Language Examination as alternative Chinese qualifications. The EDB even requests local tertiary institutes to recognise these UK-based language qualifications as substitutes for the local Chinese language requirement for academic advancement.

\subsection{Employment Opportunities}

Since the handover to the Chinese sovereignty in 1997, a growing number of jobs once open to English speakers has added a requirement of Chinese language proficiency. In the past, Indians and Pakistanis would choose to work in government departments, especially the Disciplined Forces, but the requirement for Cantonese or even Mandarin competency has ruled out most of them now. A survey conducted by the Hong Kong Unison (2016) found that most local employers are unwilling to hire EM people mainly because of communication barriers. Li (2019) finds in his qualitative study that interviewers in many professional industries would eliminate EM job seekers early in the recruitment process because of their insufficient Chinese language skills. In sum, the above warrants serious attention and the reasons behind it are worth exploring. 


\section{Literature Review}

\subsection{Critics of the Chinese Language Education Policy}

EM education, particularly in the teaching and learning of Chinese, has been an issue for public debate following the introduction of the Racial Discrimination Ordinance (RDO), which was enacted in 2009 (Hong Kong Unison, 2012). In addition, the 2016 by-census dataset shows that the participation rate of EM students in secondary and tertiary education is disproportionately low. In view of this, a special working group of the Equal Opportunities Commission has issued a report demanding that the EDB should address the imminent needs of local EM students under the RDO.

Despite the fact that legislation is in place to ensure EM students have the same education rights and benefits as their local Chinese counterparts, they still face some challenging issues. Critics from different parties such as the Hong Kong Unison and the Equal Opportunities Commission state that one of the biggest problems EM students in these public schools face is the lack of Chinese language education that caters to their needs as second/foreign language learners, despite the fact that the learning of Chinese is key to their future. However, the EDB insists that the standard mainstream Chinese curriculum together with suitable school-based adaptation is already sufficient (Curriculum Development Council, 2008).

\subsection{Critical Discourse Analysis (CDA)}

Language does not necessarily mean text, but in a broader sense includes spoken, written, visual and body gestures. A text or an image is not the result of a singular, isolated activity, but is itself a social practice. Its meaning is a negotiation between the producer and the receiver, reflecting the former's social, cultural and political beliefs, values and attitudes. In other words, all texts and images constructed by the producer's semiotic choices represent his/her own reality, ideology and interests. Kress (1993) points out that verbal, visual and even gestural signs are purposively motivated. understanding signs involves a complicated and active process requiring the reader to put himself or herself into the writer's shoes in order to decode and make meaning with reference to linguistic knowledge, cultural background and social practices. Fairclough's Critical Discourse Analysis (1995, p.98) is a three-dimensional analytic model that requires a systematic description (semiotic analysis), an accurate interpretation (analysis of encoding and decoding processes) and a comprehensive explanation (social and cultural analysis). It aims to draw out the form and function of the text (1st dimension), to understand how the text relates to the way it is produced and consumed ( 2 nd dimension), and to discover the relation of this to the society in which it takes place (3rd dimension).

Policies are made to secure particular economic, political, or power interests of the policymakers, who intend to influence actors (not) to take actions in accordance with one particular viewpoint among many competing and conflicting perspectives. CDA is seen as a visual semiotic tool to analyse the relationship between language/image and ideology/power in a text. CDA requires a critical and analytical eye to read, interpret and explain a text that is socially regulated and constrained. It is like a sharp knife slicing through multiple layers of a 
policy onion in an attempt to understand the hidden interests and disinterests of the policymaker and of the actors (Hornberger \& Johnson, 2007). However, Zhang and Mihelj (2012, p.510) opine that the drawbacks of CDA are the lack of generalisability and subjectivity of analysis due to the analyst's preconceptions.

\section{Text Analysis}

Janks (1997, p.332) states that "in unpacking a text it is important to remember that it is never possible to read meaning directly off the verbal and visual textual signs". The text chosen is a brochure titled "Non-Chinese Speaking Parent Information Package: Your Guide to Education in Hong Kong" produced by the Education Bureau, Hong Kong Special Administrative Region in 2013. The brochure aims to provide non-Chinese speaking parents with local education information so as to help them make appropriate decisions for their children's schooling. It is chosen for analysis because the brochure is intended to give information to those of the general public who are interested in education policies and services in relation to learning Chinese as a second languauge.

\subsection{Visual Signs}

Information can take different forms from words and texts (linguistics) to signs and images (semiotics). Information is nature-bound to be informative, so it should be readily communicable and understandable. Using visual signs is an effective way to represent and convey information, especially when dealing with diverse cultures.

\subsubsection{Cover Page (see Appendix 1)}

The cover page is a colourful and lively picture consisting of several elements: a rainbow overarching the sky, two birds flying underneath the rainbow, a total of ten figures divided into two rows (4 in the upper row and 6 in the lower row) holding hands standing on a yellowish sphere of land, two coconut trees to the left of the upper row of figures, and three scallop shells located at the bottom of the page.

\subsubsection{Symbolic Meaning of Rainbow: an Arch Bridge}

The rainbow, one of the most magnificent natural phenomena, has been a favourate symbolic element in many cultures. Recent studies (Aslam, 2006; Sable \& Akcay, 2010) have shown that with its ubiquitous cultural meaning, the rainbow has become a political symbol that politicians use as an essential tool to promote social harmony, unity in diversity, inclusiveness and yearning.

On the cover of the brochure, an arch-like rainbow is strategically set at the top. The rainbow represents a pathway through which EM students can enjoy pleasurable and supportive education in Hong Kong; it represents a ladder by which EM students can overcome their limitations and achieve higher success, and it represents an intermediary by which EDB's assistance is provided for EM parents and students to adapt to the local education environment. The use of the rainbow also links with the cultural meaning of an arch, which 
symbolises a gateway, an opening or a portal and it is therefore iconic for crossing over, initiation or transformation. The rainbow used here does play an ideological role influencing the target readers' perception leading them to believe in the provision of good EM education in Hong Kong.

\subsubsection{Colour Scheme of the Rainbow}

Colours can be classified into two types: (1) Natural or Primary Colours and (2) Object or Object-derived Colours (Sable \& Akcay, 2010). Natural colours, for instance rainbow scheme, are culture-general and the discrepancy of their meanings is very little among different cultures, whereas object or object-derived colours are culture-specific and have distinctive representations or implications. In this sense, colours can be perceived both universally and individually. In cross-cultural communication, the universial associations of colours are non-verbal cues promoting efficient and effective human communication. Therefore, making good use of colours can exercise powerful influences and may induce perceptions based on both instincts and socio-cultural associations (Aslam, 2006; Kress \& van Leeuwen, 2002). One can explain the ideological communication of the rainbow by pondering on the symbolism of colours (Sable \& Akcay, 2010). Using a critical eye to interpret rainbow colours will scaffold a deeper understanding of political power in policy formulation and implementation. The rainbow has the traditional scheme of colours: RED, ORANGE, YELLOW, GREEN, BLUE, INDIGO and VIOLET. Each of the seven colours has its own affective meaning that could be shared universally (Adam, 1973; Kress \& van Leeuwen, 2002). Making good use of colours can assist communication, affect one's perception, and facilitate persuasiveness, regardless of demogragphic factors such as ethnicity, sex and age (Kress \& van Leeuwen, 2002; Sable \& Akcay, 2010). Words or phrases appearing in the section of the brochure on "Pleasurable and Effective Chinese Learning" on pages 23-27 are extracted with reference to the universal meaning of each colour and then analysed with respect to the current EM education context. In other words, section 4.1.3 examines the triadic relationship associated with the use of colours, the choice of linguistic items and the criticisms made by the mass media and EM education advocacy NGOs, in order to understand how colours contribute to building a seemingly favourable Chinese learning image for EM parents and their children.

\subsubsection{The Colour Red}

Table 1. In the Rainbow Colour Scheme, Red Symbolises "Courage". Examples of Words or Phrases Corresponding to This Affective Meaning are shown in the Table Below.

\begin{tabular}{lll}
\hline & Corresponding Words/Phases & Page \# \\
\hline 1 & Support & P.26; P.27 \\
2 & encouragement & P.26 \\
3 & requires persistent accumulation & P.26 \\
4 & for greater exposure & P.26 \\
5 & learner diversity & P.27 \\
\hline
\end{tabular}


While the EDB encourages EM parents to accept the current mainstream Chinese curriculum by saying that it is flexible and effective and can cater to their children's abilities and practical needs, it allows EM students to sit for the overseas GCSE Chinese examination as an alternate qualification, which is deemed a Primary 3 level equivalent, an implicit contradiction. This is in fact a discouragement in disguise. After all, the local mainstream curriculum is meant for their Chinese counterparts with Cantonese/Mandarin as their mother tongue.

\subsubsection{The Colour Orange}

Table 2. In the Rainbow Colour Scheme, Orange Implies "Possiblility". Examples of Words or Phrases Corresponding to This Affective Meaning are Listed in the Following Table.

\begin{tabular}{lll}
\hline & Corresponding Words/Phases & Page \# \\
\hline 1 & will be consolidated & P.23 \\
2 & create & P.26 \\
3 & can bring about & P.26 \\
4 & can catch up & P.27 \\
5 & as early as possible & P.27 \\
\hline
\end{tabular}

The EDB provides two learning modes for EM parents to choose from: one is to send their children to a normal mainstream classroom to mix with local Chinese students in order to learn the Chinese language as naturally as possible. However, in a real-life education environment, language skills cannot be fully mastered without effective pedagogy and adequate resources. In a predominately Chinese society, the Chinese Language is a core subject in the Hong Kong education system. It is therefore a must-have tool for learning different kinds of subject knowledge and most schools are using Chinese as the medium of instruction. If EM students choose to join mainstream classes to study with the local Chinese, the majority of them will encounter great difficulties in understanding the teaching and learning content due to poor Chinese literacy and will adversely affect their performance in most other subjects, not to mention the likely unwelcoming environment in the mainstream classroom. This is what EM parents can predict and it therefore leads them to opt for the other mode, which is to arrange for their children to go to schools where a large number of EM students is clustered (previously known as "designated schools") for purposes of teaching and learning a simpler and modified version of the mainstream Chinese language curriculum. It seems that the EDB has given two choices for EM parents, who nonetheless know deep down that their children cannot really learn in a wholly Chinese environment, and therefore would have to put them into EM-clustered schools, knowing that their children would learn lower-level Chinese and their academic and career advancement may be possibly limited as consequences. In reality, choices for parents do not exist at all. 


\subsubsection{The Colour Yellow}

Table 3. In the Rainbow Colour Scheme, Yellow Indicates "Challenge”. Examples of Words or Phrases Corresponding to This Affective Meaning are Shown as Below.

\begin{tabular}{lll}
\hline & Corresponding Words/Phases & Page \# \\
\hline 1 & overcome problem; problems faced & P.23 \\
2 & have difficulties; overcome difficulties; teachers' difficulties & P.23,P.24,P.26 \\
3 & Finding a suitable school place & P.23,P.24 \\
4 & Never easy & P.24 \\
5 & To copy with & P.27 \\
\hline
\end{tabular}

The EDB claims that it is committed to facilitating EM students' adaptation to the local education system and mastery of the Chinese Langugae by providing a number of supportive measures such as the "immersion in Chinese language lessons" and "summer bridging programmes". The former is intended for the locally-born EM students who are likely to study, work and live in Hong Kong permanently, whereas the latter is designed for newly-arrived EM students who need to learn some survival Chinese to adapt to the Chinese speaking society. It shows that the EDB unrealistically thinks a non-Chinese speaking student would improve his/her Chinese standard dramatically in a four-week summer programme in which there is only a 3-hour lesson arranged on each week day. This is certainly a real challenge for both the EDB and EM students.

\subsubsection{The Colour Green}

Table 4. In the Rainbow Colour Scheme, Green Signifies “Cooperation”. Examples of Words or Phrases Corresponding to This Affective Meaning are Displayed in the Following Table.

\begin{tabular}{lll}
\hline & Corresponding Words/Phases & Page \# \\
\hline 1 & networked & P.26 \\
2 & vaious parties & P.26 \\
3 & join hands; have joined & P.26 \\
4 & invite; cordially invited & P.26 \\
5 & collaborate with & P.27 \\
\hline
\end{tabular}

The EDB emphasises its collaborative efforts with a thrid party in providing various support services for EM students. However, it has too closely identified itself with some of the services offered by various non-governmental organisations to ethnic minorities in the community. Some NGOs provide short-term survival language courses and occasional cultural activities for EM youngsters. However. these organisations do not have the responsibility to offer effective and comprehensive Chinese education for EM students. It 
seems that the EDB is attempting to cast the best possible light on the existing situation by including in its brochure services which have little to do with it and which in themselves offer only bandaid solutions. This is somewhat misleading.

\subsubsection{The Colour Blue}

Table 5. In the Rainbow Colour Scheme, Blue Represents "Far Horizons" Examples of Words or Phrases Corresponding to This Affective Meaning are Illustrated in the Following Table.

\begin{tabular}{lll}
\hline & Corresponding Words/Phases & Page \# \\
\hline 1 & enhancing the effectiveness; enhance their motivation; & P.26, 27 \\
2 & promote exchange & P.27 \\
3 & scaffold their learning & P.27 \\
4 & build a strong language foundation & P.27 \\
5 & Develop a holistic and balanced school-based curriculum & P.27 \\
\hline
\end{tabular}

The no-loser refrom policy has been enforced since 2001 in response to the ever-changing global economic landscape and the emergence of a knnowledge-based society. The core Chinese language curriculum for all students is meant to address this no-loser policy. Yet, when it comes to EM education, it is far from adequate and the supportive measures provided by the EDB are just piecemeal. Under this policy, EM secondary school students will graduate with low Chinese proficiency, which hinders their chances for further studies and employment. The unfair Chinese language education curriculum may shatter the dream of success in the lifetime of some, if not all EM students due to the lack of sufficient Chinese language skills. The likelihood of underachievement will pass from generation to generation. There is a strong need to develop a "Chinese as a foreign language" policy that suits the learning needs of non-Chinese speakers in Hong Kong, especially those of ethnic minorities.

\subsubsection{The Colour Indigo}

Table 6. In the Rainbow Colour Scheme, Indigo Denotes "Empathy". Examples of Words or Phrases Corresponding to This Affective Meaning are Displayed in the Table Below.

\begin{tabular}{lll}
\hline & Corresponding Words/Phases & Page \# \\
\hline 1 & very concerned & P.23 \\
2 & teach patiently & P.23 \\
3 & provide remedial programmes & P.24;P.25 \\
4 & offering practical help & P.26 \\
5 & public caring & P.26 \\
\hline
\end{tabular}




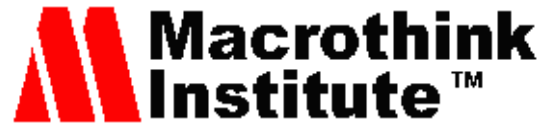

The EDB seems to sympathise with the difficulties faced by EM students in taking the mainstream Chinese curriculum through the provision of alternative assessments such as the GCSE and the IGCSE. In fact, it indirectly admits its inadequate provision for this group of students. Besides, the "designated school" system may promote de facto segregation, as these schools are only located in certain impoverished districts such as Sham Shui Po and Tin Shui Wai. This may result in a disproportionately high number of EM students attending racially isolated schools. Besides, public attitude towards ethnic minorities is not positive as the survey report indicates that about $33 \%$ of Chinese parents are uncomfortable sending their children to a school which accepts a high number of EM students (Census and Statistics Department, 2017). The same phenomenon is also evident in a survey on racial acceptance by the Hong Kong Unison (2012).

\subsubsection{The Colour Violet/Purple}

Table 7. In the Rainbow Colour Scheme, Violet or Purple is the Colour of "Friendship". Examples of Words or Phrases Corresponding to This Affective Meaning are Demonstrated in the Following Table.

\begin{tabular}{lll}
\hline & Corresponding Words/Phases & Page \# \\
\hline 1 & make the classroom very lively & P.24 \\
2 & buddy & P.25 \\
3 & ambassadors & P.26 \\
4 & peer & P.26 \\
5 & various parties & P.26 \\
\hline
\end{tabular}

The EDB invites local students to help their EM classmates to learn the Chinese language. However, no supportive measures are mentioned to raise the sensitivity of local parents and students towards racial and cultural acceptance. How can a lively and harmonous learning atmosphere be created between local and EM students under these circumstances? This seems to be one of EDB's empty slogans. Besides, it is contradictory for the EDB to achieve its objectives of the inclusive education policy on one hand, while on the other, encourage EM parents to send their children to its designated schools.

Having indulged in the rainbow image on the front cover with its unmistakable interpretation, it would be less than frank for the EDB to claim that the rainbow colours on subsequent pages are not intended to extend that imagery based on the assumption that the meanings of the rainbow colours are universal but not cultural.

\subsubsection{Cartoon Figures}

There are ten cartoon figures joining hands standing under the rainbow, each of them wearing their national costume. Table 1 shows the gender and ethnicity of each figure. 


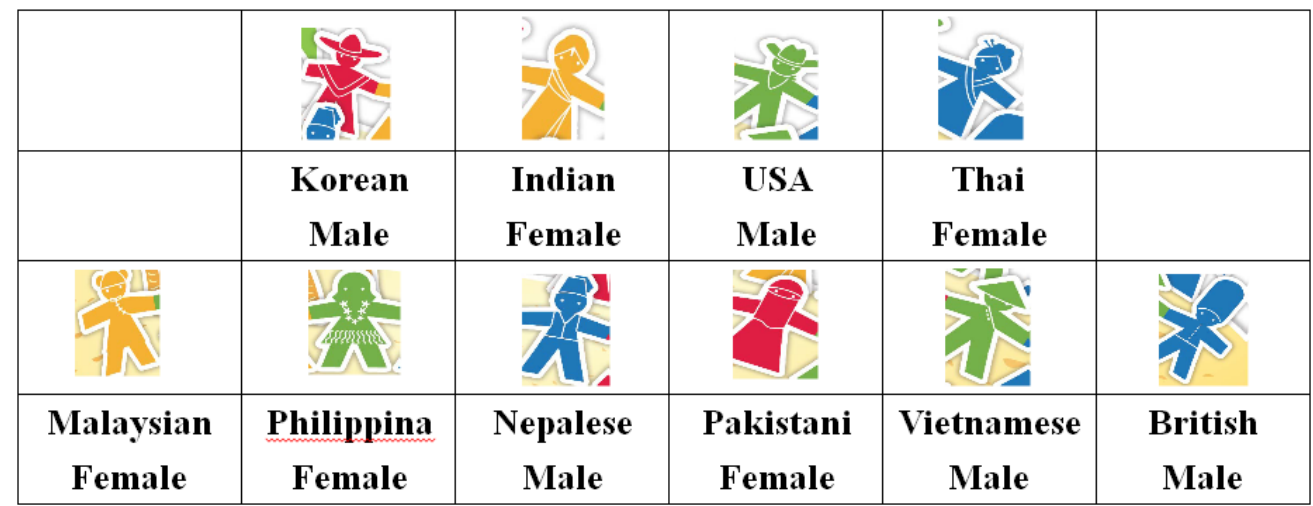

Figure 1. Gender and Ethinicity of the Figures Shown on the Cover Page

The same number of males and females, i.e. 5 men and 5 women, represents gender equality. They are holding hands standing on a yellow surface. Hand-holding is known as a sign of fondness, rapport, respect, concern, trust, and perhaps love. It reinforces the feeling of social harmony and cohesion among different ethnicities in the Hong Kong society. Besides, the HKSAR has agreed to international instruments such as the International Convention on the Elimination of All Forms of Racial Discrimination and the International Covenant on Economic, Social and Cultural Rights. Domestically, the Sex Discrimination Ordinance as well as the Race Discrimination Ordinance have specified individual rights to equal education opportunities regardless of gender or race. This can be a gesture of showing compliance with the aforesaid international instruments and domestic ordinances.

\subsubsection{Shells}

Three scallop shells can be found at the bottom of the cover. According to Chinese religious beliefs, especially those of Buddhism, the use of scallop shells is an emblem of authority, power as well as sovereignty. Having been washed to the shores by ocean waves, they may create a feeling that EM immigrants for whatever reasons uproot themselves from overseas homes and take root in Hong Kong.

\subsubsection{Birds}

Two V-shaped, bird-like books fly above the cartoon figures. Most people see birds and their proximity with the sky as a symbol of freedom, or even of the future. Besides, books have a direct association with education. The symbol may therefore suggest that with a sound education system in Hong Kong, EM immigrants will be able to have a bright future.

\subsubsection{Yellow Surface}

The colour yellow generally gives a happy, uplifting feeling. Chinese people pay high regard to yellow because the Chinese culture was originated on the "Yellow Plateau", the cradle of the Chinese nation was the "Yellow River", and the descendants of the Yellow Emperor have "yellow skin". Since ancient times, yellow has been inseparably linked with Chinese traditional culture. In addition, yellow represents the colour of the center, symbolising the 
colour of the earth. In China, there is an idiom saying that "Yellow generates Yin and Yang" (Note 2), reflecting yellow's orthodox position in the center among other colours. All the cartoon figures are standing on a yellow sphere. This creates an impression that they are living in the Chinese community in a harmonious and inclusive manner without being discriminated against by the Hong Kong Government and its people.

In Section 4.1, the visual images and colours work well together to create a sense of exotic education oasis for EM parents in Hong Kong who are in need of guidance and assistance in terms of their children's education. However, they are not given any agency and voice.

\subsection{Verbal Signs}

\subsubsection{Genre}

A genre is a conventionalised way of using language in a particular social situation so as to serve various ostensible purposes (Fairclough, 1992). There are several aspects to characterise a specific genre. Swales (1990) and Bhatia (1993) consider that the rationale for a genre is a set of communicative purposes which it serves. This set of purposes determines the particular features of the genre in terms of structure, style and content. Berkenkotter and Huckin (1995:4), drawing on Bakhtin, see genres as "dynamic rhetorical forms that are developed from an actor's responses to recurrent situations". Fairclough (1992, p.126) observes that rather than being only a specific type of text, a genre can involve a specific mode of text production, distribution and consumption; that is to say, a text can mix two or more different genres. This is what Fairclough has termed "genre hybridity" (2000, p.163).

Table 8. Samle Lexical Devices with Judgemental and Appreciateive Functions

\begin{tabular}{ll}
\hline Judgmental & Appreciateive \\
\hline more quickly (P.23)(P.26) & pleasurable (P.23) \\
good (P.24) & effective (P.23)(P.26)(P.27) \\
additional (P.25) & lively (P.24) \\
more importantly (P.26) & professionnal (P.24)(P.27) \\
more directly (P.26) & successful (P.25) \\
greater (P.26) & hormonious (P.26) \\
more systematically (P.27) & caring (P.26) \\
& pleasant (P.26) \\
& rich (P.26) \\
& advantageous (P.26) \\
& holictic (P.27) \\
& flexible (P.27) \\
\hline
\end{tabular}


The guide was selected for the analysis because by its nature, it should be perceived by the target readership to be a disinterested, objective and impersonal text that only gives information on the local education policies and services to EM parents and students. However, when using the dimension of interestedness to classify its genre, it is more like a brochure, which aims to be a communicative instrument purposively employed by an organisation to achieve an intended goal. It obviously falls into the pomotional genre that carries judgmental and appreciative functions by the use of positive vocabulary (Martin, 2004). The judgmental function aims to describe something with vocabulary whose positive value is clear to the informed reader - plesaurable, professional, successful, etc; whereas the appreciative function aims to describe something with vocabulary whose value is clear in a specific context - good, poor, more, etc. Table 3 shows the instances of lexis serving these two promotional functions.

The EDB tries to use an informative text (a guide) as a promotional piece (a brochure) in an attempt to promote its helpful and caring image to EM parents and students, through selective use of positive vocabulary.

\section{Conclusion}

Ethnic minorities have long been an integral part of Hong Kong's social fabric and economic growth, and the EM students' multicultural outlook will no doubt play a positive role in the city's future competitiveness in the era of rapid globalisation. The guide issued by the EDB seems to contravene its existing education policies and social expectations. It is recommended that the EDB should ensure equitable educational provision and recognise the systemic challenges of its Chinese language curriculum encountered by EM parents and their children. By drawing on the analytic framework of Fairclough's CDA, this paper has given a general visual and textual analysis of an informative guide in the form of a promotional brochure. The author has uncovered the hidden ideologies of the Chinese Language education policy being advanced to persuade the EM parents and students in Hong Kong through examination of the inter-relationship between the visual and textual signs that shape and construct meanings in the reader's mind. Therefore, the findings of this paper has made a theoretical contribution to the existing literature on Critical Discourse Analysis that the interplay between visual and textual symbols will generate affective associations to influence the perception of the readers. Because of the limited scope of this paper, only the cover and pages 23-27 were chosen for analysis with respect to the current socially and politically charged issues of education for ethnic minority students. Other visual and textual aspects can be reserved for further exploration and discussion.

\section{References}

Adams, F. M., \& Osgood, C. E. (1973). A cross-cultural study of the affective meanings of color. Journal of Cross-Cultural Psychology, 4, 135-156. https://doi.org/10.1177/002202217300400201 
Aslam, M. (2006). Are you selling the right colour? A cross-cultural review of colours as a marketing cue. Journal of Marketing Communications, 12, 15-30. https://doi.org/10.1080/13527260500247827

Benitez, M. A. (2011, October 24). Fears for minority students. The Standard. Retrieved 10 June, 2020 from http://www.thestandard.com.hk/news_detail.asp?pp_cat=11\&art_id=116319\&sid=3418 $2555 \&$ con_type $=1 \& d$ _str $=20111024 \&$ isSearch $=1 \&$ sear_year $=2011$

Berkenkotter, C., \& Huckin, T. N. (1995). Genre Knowledge in Disciplinary Communication: Cognition/Culture/Power. Hillsdale, New Jersey: Erlbaum.

Bhatia, V. K. (1993). Analysing Genre: Language Use in Professional Settings. London: Longman.

Census and Statistics Department. (2017). Hong Kong 2016 Population By-census-Summary $\begin{array}{lllll}\text { results. } & \text { Retrieved } & 9 & \text { June, } & 2020\end{array}$ https://www.censtatd.gov.hk/hkstat/sub/sp459.jsp?productCode=B1120094

Cheng, J. (2011, October 10). Rita Fan urges good language training. South China Morning Post. Retrieved 9 June, 2020 from http://www.scmp.com/article/981438/rita-fanurges-good-language-training

Chong, S. (2011). Critical perspective on new arrival children from mainland China in Hong Kong: Government policies, school practices, and teacher responses. In J. Phillion, M. T. Hue, \& Y. Wang (Eds.), Minority Students in East Asia: Government Policies, School Practices and Teacher Responses (pp. 105-122). London: Routledge.

Cirlot, J. E. (1981). A Dictionary of Symbols. New York: Philosophical Library.

Curriculum Development Council. (2008). Developing a supplementary guide to the Chinese language curriculum for non-Chinese speaking students. Retrieved 9 June, 2020, from http://www.edb.gov.hk/FileManager/TC/Content_93/devt_of_sg_to_chi_ncs_e.pdf

Equal Opportunities Commission. (2011). Education for All: Report on the Working Group on Education for Ethnic Minorities. Retrieved 9 June, 2020 from http://www.eoc. org.hk/EOC/Upload/UserFiles/File/EducationReportE.pdf

Fairclough, N. (1992). Discourse and Social Change. Cambridge: Polity Press.

Fairclough, N. (1995). Critical Discourse Analysis. London: Longman.

Fairclough, N. (2000). Discourse, social theory, and social research: the discourse of welfare $\begin{array}{llll}\text { reform. } & \text { Journal } & \text { Sociolinguistics, } & 4(2),\end{array}$ https://doi.org/10.1111/1467-9481.00110

Hong Kong Unison. (2012). Racial acceptance survey report. Retrieved 9 June, 2020 from http://www.unison.org.hk/DocumentDownload/Researches/R201203\%20Racial\%20Acc eptance \%20Survey\%20Report.pdf?subject=Enquiry\%20for \%20Research\%20hard\%20c opy 
Hong Kong Unison. (2016). Chinese Language Requirements in the Hong Kong Job Market: A Survey on Job Advertisements. Hong Kong: Unison Hong Kong.

Hornberger, N. H., \& Johnson, D. C. (2007). Slicing the onion ethnographically: Layersand spaces in multilingual language education policy and practice. TESOL Quarterly, 41(3), 509-532. https://doi.org/10.1002/j.1545-7249.2007.tb00083.x

Hue, M. T. (2011). Building a culturally responsive school: Cross-cultural experiences of ethnic minority students in Hong Kong schools. In J. Phillion, M. T. Hue, \& Y. Wang (Eds.), Minority students in East Asia: Government Policies, School Practices and Teacher Responses (pp. 141-154). New York, NY; London, England: Routledge. https://doi.org/10.4324/9780203813317

Janks, H. (1997). Critical Discourse Analysis as a Research Tool. Discourse: Studies in the Cultural Political of Education, 18(3), 329-342. https://doi.org/10.1080/0159630970180302

Kress, G. (1993). Genre as social process. In. B. Cope and M. Kalanztis (Eds.), The Powers of Literacy: A Genre Approach to Teaching Writing (pp. 22-37). London: Falmer Press.

Kress, G., \& van Leeuwen, T. (2002). Colour as a semiotic mode: notes for a grammar of colour. Visual Communication, Arnold. https://doi.org/10.1177/147035720200100306

Li. E. (2019). Chinese language needs of South Asian undergraduates: a case study in a self-financing vocational institute in Hong Kong. Doctoral dissertation, University of Bristol.

Martin, J. R. (2004). Mourning: how we get aligned. Discourse and Society, 15(2-3), 321-344. https://doi.org/10.1177/0957926504041022

Plüss, C. (2000). Transnational identities: The Hong Kong Indians. The International Scope Review, 2(4). $\quad$ Retrieved 9 June, 2020 from http://tscf.vefir.net/PUBLICATIONS/TISR_journal1/volume\%202000/issue4/pluss.htm

Sable, P., \& Akcay, O. (2010). Color: Cross Cultural Marketing Perspectives As To What Governs Our Response To It. American Society of Business and Behavioral Sciences, 17(1), 950-954.

Swales, J. M. (1990). Genre Analysis. English in Academic and Research Settings. Cambridge: Cambridge University Press.

Thapa, C. B. (2012). Nurture the talents of EM students. Ethnic Voice Weekly, 1(3), 4.

Zhang, M., \& Mihelj, S. (2012). Hong Kong identity and the press-politics dynamics: a corpus-assisted discourse study. Aisan journal of Communication, 22(5), 506-527. https://doi.org/10.1080/01292986.2012.701315 


\section{Macrothink}

Notes

Note 1. The brochure is downloadable at: https://www.edb.gov.hk/en/student-parents/ncs-students/support-to-student-and-parents/ncs-p arent-information-package.html

Note 2. Chinese have a saying, "Yellow generates Yin and Yang.", thus making it the colour of neutrality placed in the centre of all colours - the "golden middle" of everything. It represents the "centre", or "zenith" - a stabilizing energy and the balance of Yin and Yang.

\section{Appendix 1}

The cover page of the brochure titled "Non-Chinese Speaking Parent Information Package: Your Guide to Education in Hong Kong".

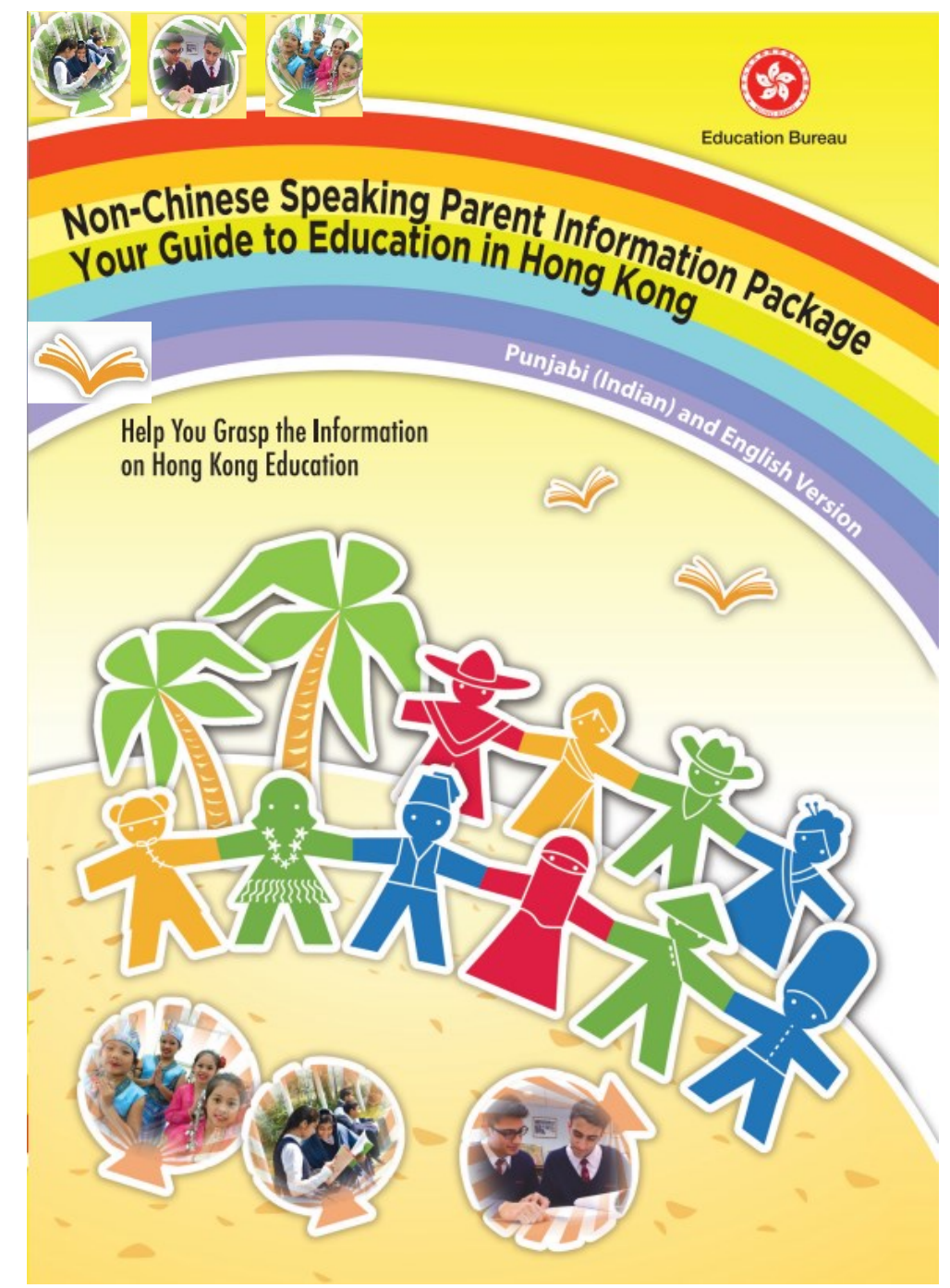




\section{Copyrights}

Copyright for this article is retained by the author(s), with first publication rights granted to the journal.

This is an open-access article distributed under the terms and conditions of the Creative Commons Attribution license (http://creativecommons.org/licenses/by/4.0/) 